\title{
Influence of Al impurities on the electrical properties of $\mathrm{ZnO}$ films
}

\author{
S. I. Rembeza ${ }^{\dagger, 1}$, R.E. Prosvetov ${ }^{1}$, E. S. Rembeza ${ }^{2}$, A. A. Vinokurov ${ }^{1}$, \\ V. A. Makagonov' ${ }^{1}$, B. L. Agapov² \\ †rembeza@yandex.ru
}

${ }^{1}$ Voronezh State Technical University, 84 20-letiya Oktyabrya St., Voronezh, 394026, Russia

${ }^{2}$ Voronezh State University, 1 Universitetskaya Sq., Voronezh, 394018, Russia

\begin{abstract}
The paper presents the results of studies of the structure, electrical and optical properties of $\mathrm{ZnO}$ films with Al content from 1 to 5 at.\% obtained by the method of ion-beam sputtering of a composite ceramic target in an argon atmosphere. The composite target is a rectangular $\mathrm{ZnO}$ ceramic plate with several bands of $\mathrm{Al}_{2} \mathrm{O}_{3}$ corundum unevenly distributed over the $\mathrm{ZnO}$ surface. In one sputtering cycle, 10 samples were obtained with an aluminum concentration of 1 to 5 at.\% as the results of the analysis of the energy dispersion of the second electrons. After deposition, $\mathrm{ZnO}$ films were partially crystallized and contained one phase of hexagonal wurtzite with increased parameters $a$ and $c$. The grain size of the films was estimated using the Scherrer equation and showed a tendency for the grain sizes to change with increasing Al concentration in $\mathrm{ZnO}$ films. X-ray diffraction data were confirmed by studying the surface morphology using atomic force microscopy. Measurement of the electrical parameters of the films showed that the smallest resistivity $\left(\sim 4 \cdot 10^{-3} \mathrm{Ohm} \cdot \mathrm{cm}\right)$ is observed in $\mathrm{ZnO}$ films with 1 at.\% Al. As the $\mathrm{Al}$ concentration in $\mathrm{ZnO}$ increases, the resistivity of the films increases, reaching the value $\rho=250 \mathrm{Ohm} \cdot \mathrm{cm}$ at $5 \mathrm{at} . \% \mathrm{Al}$. A possible model of the effect of $\mathrm{Al}$ impurity on the electrical properties of $\mathrm{ZnO}$ films is considered. Studies of the optical properties of the samples showed that all films are highly transparent $(\sim 70 \div 90 \%)$ in the visible light range. The interference bandwidths provide an estimate of the value of the refractive index of $\mathrm{ZnO}: \mathrm{Al}$ films. From the light absorption spectra, the values of the band gap of $\mathrm{ZnO}: \mathrm{Al}$ samples were determined and a slight increase in the band gap of $\mathrm{ZnO}: \mathrm{Al}$ with an increase in the $\mathrm{Al}$ concentration in films was established. The mechanism of this behavior of Al impurity in $\mathrm{ZnO}$ is discussed. Possible areas of application for $\mathrm{ZnO}$ films with $\mathrm{Al}$ impurities are considered.
\end{abstract}

Keywords: ion beam sputtering, ZnO films, impurity Al, X-ray analysis, electrical and optical properties.

УДК: 538.975

\section{Влияние примеси $\mathrm{Al}$ на электрофизические свойства пленок ZnO}

\author{
Рембеза С. И. ${ }^{\dagger, 1}$, Просветов Р.Е. ${ }^{1}$, Рембеза Е. С. ${ }^{2}$, Винокуров А. А. ${ }^{1}$,
}

Макагонов В. А. ${ }^{1}$, Агапов Б. Л. ${ }^{2}$

${ }^{1}$ Воронежский государственный технический университет, ул. 20-летия Октября, 84, Воронеж, 394006, Россия ${ }^{2}$ Воронежский государственный университет, Университетская пл., 1, Воронеж, 394018, Россия

В работе представлены результаты исследований структуры, электрических и оптических свойств пленок $\mathrm{ZnO}$ с содержанием $\mathrm{Al}$ от 1 до 5 ат.\%, полученных методом ионно-лучевого распыления составной керамической мишени в атмосфере аргона. Составная мишень представляет собой прямоугольную керамическую пластину ZnO c несколькими полосами корунда $\mathrm{Al}_{z} \mathrm{O}_{3}$, неравномерно распределенными на поверхности $\mathrm{ZnO}$. За один цикл напыления были получены 10 образцов с концентрацией алюминия от 1 до 5 ат.\% по данным энергодисперсионного анализа вторичных электронов. Сразу после напыления пленки ZnO были частично кристаллизованы и содержат одну фазу гексагонального вюрцита с увеличенными параметрами $a$ и $c$. Размер зерна пленок оценивался по формуле Шеррера и показал тенденцию к изменению размеров зерен по мере увеличения концентрации Al в пленках ZnO. Данные 
рентгеноструктурного анализа подтверждены исследованием морфологии поверхности с помощью атомно-силовой микроскопии. Измерение электрических параметров пленок показали, что наименьшее удельное сопротивление $\left(\sim 4 \cdot 10^{-3} \mathrm{OM} \cdot \mathrm{cm}\right)$ наблюдается в пленках $\mathrm{ZnO}$ с 1 ат.\% Al. По мере увеличения концентрации $\mathrm{Al}$ в $\mathrm{ZnO}$ удельное сопротивление пленок возрастает, достигая значения $\rho=250$ Ом·см при 5 ат.\% Al. Рассмотрена возможная модель влияния примеси $\mathrm{Al}$ на электрические свойства пленок $\mathrm{ZnO}$. Исследования оптических свойств образцов показали, что все пленки отличаются высокой прозрачностью $(\sim 70 \div 90 \%)$ в видимом диапазоне света. По интерференционным полосам пропускания приведена оценка величины коэффициента преломления пленок ZnO:Al. Из спектров поглощения света определены значения ширины запрещенной зоны образцов $\mathrm{ZnO}: \mathrm{Al}$ и установлено небольшое увеличение ширины запрещенной зоны $\mathrm{ZnO}: \mathrm{Al}$ с увеличением концентрации $\mathrm{Al}$ в пленках. Обсужден механизм такого поведения примеси $\mathrm{Al}$ в ZnO. Рассмотрены возможные сферы применения пленок ZnO с примесью $\mathrm{Al}$.

Ключевые слова: ионно-лучевое распыление, пленки $\mathrm{ZnO}$, примесь $\mathrm{Al}$, рентгеноструктурный анализ, электрические и оптические свойства.

\section{1. Введение}

Тонкие полупроводниковые пленки $\mathrm{ZnO}$ имеют ширину запрещенной зоны более 3 эВ, прозрачны в видимом диапазоне света, обладают прямозонной структурой, из-за наличия дефицита кислорода характеризуются $n$-типом проводимости и широко используются в современной электронике [1]. Пленки $\mathrm{ZnO}$ применяются в газовой сенсорике [2], в прозрачной электронике [3], в качестве светоизлучающих структур [4], прозрачных проводящих электродов [5] и в других областях науки и техники. Для изготовления пленок $\mathrm{ZnO}$ и их легирования примесями используются различные методы синтеза. Например, золь-гель технологии $[6,7,8]$, спрей-пиролиз [9], лазерное импульсное осаждение [10], магнетронное распыление на переменном токе [11] и другие.

Трехвалентный ион алюминия $\mathrm{Al}^{3+}$ при замещении двухвалентного цинка $\mathrm{Zn}^{2+}$ в кристаллической решетке $\mathrm{ZnO}$ будет вести себя как донорная примесь, что широко используется для изготовления прозрачных высокопроводящих слоев $\mathrm{ZnO}$ в прозрачной электронике [11] и солнечной энергетике [12]. Влияние примесных атомов на свойства $\mathrm{ZnO}$ зависит не только от структуры их электронных оболочек, но и от предельной растворимости и места локализации примесей в кристаллической решетке ZnO. В частности, примеси атомов V группы образуют в кристаллической решетке $\mathrm{ZnO}$ сложный дефект с участием вакансий цинка и ведут себя как акцепторы, позволяющие изготавливать пленки $\mathrm{ZnO}$ р-типа проводимости для различных изделий электроники [13].

Литературные данные о поведении $\mathrm{Al}$ в $\mathrm{ZnO}$ неоднозначны. У одних авторов с увеличением концентрации $\mathrm{Al}$ электросопротивление пленок $\mathrm{ZnO}$ сначала уменьшается, а свыше 1 ат.\% сопротивление возрастает [9]. У других исследователей [7] с ростом концентрации $\mathrm{Al}$ сопротивление пленок $\mathrm{ZnO}$ растет непрерывно, по мнению авторов за счет выхода примеси в междоузлия решетки ZnO. Однако, по данным работы [14] добавление в $\mathrm{ZnO}$ примеси $\mathrm{Al}$ от 1 до 5 об.\% приводит к монотонному росту электропроводности пленок $\mathrm{ZnO}$ и при 5 об.\% $\mathrm{Al}$ проводимость чистого $\mathrm{ZnO}$ удваивается. Во всех цитируемых статьях количество примести $\mathrm{Al}$ в пленках $\mathrm{ZnO}$ определялось не экспериментальным, а расчетным путем по содержанию $\mathrm{Al}$ в прекурсоре.
Цель данной работы - исследование влияния количества примеси $\mathrm{Al}$ в пленках $\mathrm{ZnO}$ на структуру, морфологию, электрические и оптические свойства пленок $\mathrm{ZnO}$, синтезированных ионно-лучевым распылением керамических мишеней в атмосфере аргона. Определение оптимальной концентрации $\mathrm{Al}$ в пленках $\mathrm{ZnO}$ необходимо для их применения в качестве прозрачных электропроводящих покрытий в составе солнечных элементов и других изделий электроники.

\section{2. Изготовление образцов и методика эксперимента}

Тонкие пленки $\mathrm{ZnO}$ с примесью $\mathrm{Al}$ изготавливались методом ионно-лучевого распыления составной керамической мишени [15] размером $280 \times 80$ мм, и содержащей керамические бруски $\mathrm{ZnO}$ площадью $80 \times 10$ мм, полученные методом сухого прессования порошка $\mathrm{ZnO}$ (ЧДА). На поверхности мишени $\mathrm{ZnO}$ закреплялись с переменным шагом тонкие полоски корунда $\mathrm{Al}_{2} \mathrm{O}_{3}$ шириной 3 мм в количестве 5 штук. В качестве подложек использовались предметные стекла (10 штук) размером $25 \times 75$ мм. Распыление осуществлялось в атмосфере Ar чистотой 99.992\%. Неравномерное расположение навесок корунда на поверхности мишени $\mathrm{ZnO}$ позволило в одном технологическом режиме осаждения получить различные концентрации легирующего элемента (Al) в пленке $\mathrm{ZnO}$ в зависимости от положения подложки относительно керамической мишени (Рис. 1).

Толщина синтезированных пленок измерялась с помощью интерференционного микроскопа МИИ-4, элементный состав образцов контролировался методом энергодисперсионного анализа вторичных электронов с помощью электронно-зондовой приставки INCA x-sight (Oxford Instruments) к электронному микроскопу JEOL JSM-6380LV. Фазовый состав пленок исследовался методом рентгеновского дифракционного анализа на установке Bruker D2 Phaser с обработкой данных при помощи программы Bruker DIFFRAC SUITE EVA 3.0. Морфология пленок контролировалась методом атомно-силовой микроскопии на установке FemtoScan-1. Оптические свойства образцов исследовались с помощью двухлучевого спектрофотометра СПЕКС ССП-715М, электрические параметры пленок $\mathrm{ZnO}$ измерялись четырехзондовым методом (установка ВИК-УЭС). 

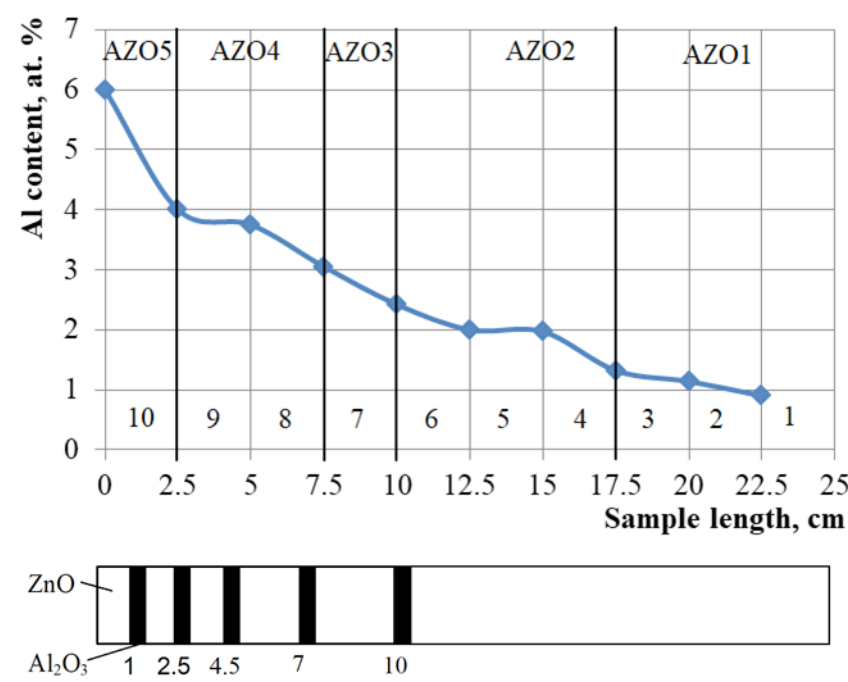

Рис. 1. Распределение содержания примеси $\mathrm{Al}$ по длине подложки. Все 10 стеклянных подложек размещены на длине 25 см. Вверху обозначена группа образцов со средним количеством алюминия в $\mathrm{ZnO}$ от 1 до 5 ат.\%. Внизу - схема размещения корундовых вставок (темные полосы шириной 3 мм) на мишени из $\mathrm{ZnO}$.

Fig. 1. The distribution of the content of $\mathrm{Al}$ impurities along the substrate. All 10 glass substrates are placed at a length of $25 \mathrm{~cm}$. Above is indicated a group of samples with an average amount of aluminum in $\mathrm{ZnO}$ from 1 to 5 at.\%. Below - layout of corundum inserts (dark zones width $3 \mathrm{~mm}$ ) on a $\mathrm{ZnO}$ target.

\section{3. Элементный состав и структура пленок}

Использование составной керамической мишени и выбранные режимы ионно-лучевого распыления позволили получить в одном технологическом процессе распределение в 10 образцах $\mathrm{ZnO}$ примеси $\mathrm{Al}$ по данным энергодисперсионного анализа с концентрацией от 1 до 6 ат.\% (Рис. 1). Стеклянная подложка содержала 10 образцов пленок $\mathrm{ZnO}$ шириной 2.5 см каждый c различным количеством примеси $\mathrm{Al}$. Все образцы были разбиты на 5 групп со средним содержанием $\mathrm{Al}$ от 1 до 5 ат.\% и обозначены как AZO1 (1 ат.\% Al), AZO2 (2 ат.\% Al), AZO3, AZO4 и AZO5. Толщина пленок составляла $2 \pm 0.2$ мкм и возрастала с уменьшением концентрации алюминия в пленках $\mathrm{ZnO}$ (Табл. 2). Уменьшение толщины пленок в местах увеличения числа навесок корунда, возможно, обусловлено меньшей скоростью распыления корундовой мишени по сравнению с керамикой $\mathrm{ZnO}$.

Для определения фазового состава полученных слоев был проведен рентгеноструктурный анализ образцов ZnO-Al. Дифрактограммы были получены на рентгеновском дифрактометре Bruker D2 Phaser с использованием медного излучения $\left(\lambda_{\text {Сuка1 }}=1.54 \AA\right)$. Обработка результатов проводилась в программе DIFFRAC SUITE Eva 3.0 с кристаллографическими базами данных ICDD PDF-2 2012 и TOPAS 4.2.

Анализ полученных дифрактограмм (Рис. 2) показал, что тонкие пленки $\mathrm{ZnO}$ характеризуются одной кристаллической фазой с гексагональной решеткой вюрцита (пространственная группа Р63mc). Сравнивая интенсивности рефлексов с данными карточки

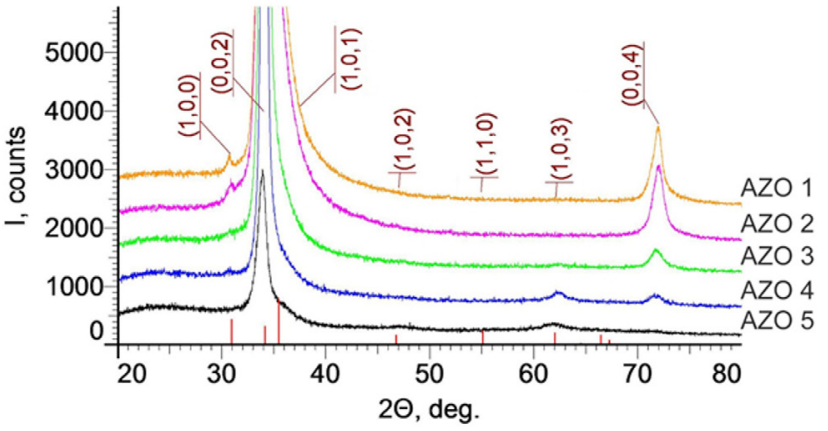

Puc. 2. (Color online) Картины дифракции рентгеновских лучей от тонких пленок $\mathrm{ZnO}-\mathrm{Al}$ с различным содержанием $\mathrm{Al}$.

Fig. 2. (Color online) $\mathrm{X}$-ray diffraction patterns from thin $\mathrm{ZnO}-\mathrm{Al}$ films with different $\mathrm{Al}$ contents.

PDF 01-070-8070 базы данных ICDD PDF 2012 можно сделать вывод, что пленки $\mathrm{ZnO}-\mathrm{Al}$ являются сильно текстурированными с осью текстуры <001>, что на дифрактограммах Рис. 2 проявляется в виде увеличения интенсивностей от рефлексов (002) и (004).

Оценка размеров кристаллитов проводилась по формуле Шеррера

$$
D=\frac{k \lambda}{\beta \cdot \cos \theta},
$$

где $D-$ средний размер кристаллов, $K-$ безразмерный коэффициент формы частиц (постоянная Шеррера), $\lambda-$ длина волны рентгеновского излучения, $\beta$ - ширина рефлекса на полувысоте (в радианах), $\theta-$ угол дифракции (брэгговский угол). Результаты приведены в Табл. 1 и на Рис. 3.

По причине присутствия на дифрактограммах малого количества пиков, не удается разделить вклад микронапряжений и размера частиц в уширение рефлексов, поэтому размеры кристаллитов были определены в предположении, что размерный эффект доминирует. При этом следует учесть, что определенный таким образом размер кристаллитов относится к направлению [001] кристаллической решетки $\mathrm{ZnO}$, которое, учитывая текстурированность полученных

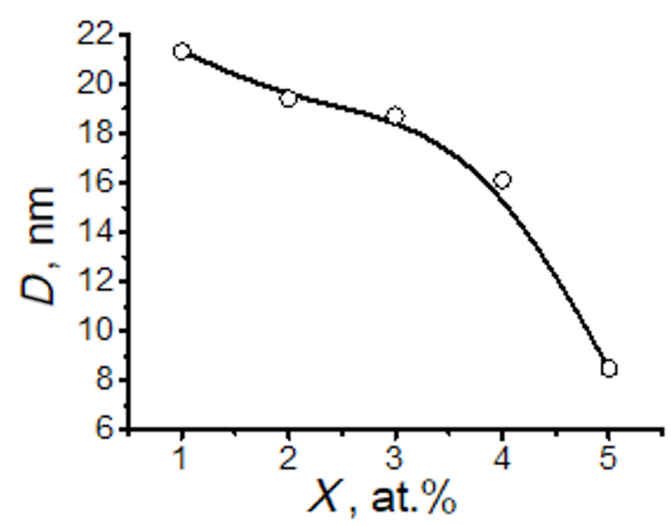

Рис. 3. Зависимость размеров кристаллитов тонких пленок $\mathrm{ZnO}-\mathrm{Al}$, определенных по формуле (1) от содержания $\mathrm{Al}$ в образцах.

Fig. 3. Dependence of crystallite sizes of thin $\mathrm{ZnO}: \mathrm{Al}$ films, determined by formula (1) on $\mathrm{Al}$ content in samples. 
Табл. 1. Параметры элементарной ячейки $\mathrm{ZnO}$ при легировании $\mathrm{Al}$. Table 1. $\mathrm{ZnO}$ unit cell parameters for $\mathrm{Al}$ doping.

\begin{tabular}{|c|c|c|c|}
\hline $\begin{array}{c}\text { Образец } \\
\text { Sample }\end{array}$ & $a, \AA$ & $c, \AA$ & $\begin{array}{c}D, \text { нм } \\
D, \mathrm{~nm}\end{array}$ \\
\hline AZO5 & 3.274 & 5.287 & 8.5 \\
\hline AZO4 & 3.266 & 5.268 & 16.1 \\
\hline AZO3 & 3.254 & 5.262 & 18.7 \\
\hline AZO2 & 3.262 & 5.25 & 19.4 \\
\hline AZO1 & 3.305 & 5.251 & 21.3 \\
\hline
\end{tabular}

пленок, находится перпендикулярно к плоскости подложки. Таким образом, размер кристаллитов $D-$ это размер кристаллитов $\mathrm{ZnO}$, измеренный в направлении, перпендикулярном плоскости пленки. В направлениях вдоль плоскости пленки размеры кристаллитов могут отличаться. Рассчитанные параметры решетки и размеры зерен приведены в Табл. 1. Параметры решетки из базы данных: $a=3.249 \AA$; $c=5.206 \AA$. В предварительных экспериментах по напылению чистого $\mathrm{ZnO}$ методом ионно-лучевого распыления нами для параметров решетки $a$ и $b$ были получены значения 3.36 и $5.24 \AA$ соответственно [16].Это значительно больше параметров решетки согласно данным карточки PDF 01-070-8070: $a=3.249 \AA ; \quad c=5.206 \AA$, однако лучше согласуется с данными, полученными в настоящей работе.

Таким образом, рентгенофазовый анализ показал, что с увеличением концентрации $\mathrm{Al}$ в пленках $\mathrm{ZnO}$ растет величина параметра $c$ решетки вюрцита и одновременно уменьшается средний размер зерна поликристалла. Эти результаты согласуются с данными работы [17] и подтверждаются исследованиями морфологии поверхности методом атомно-силовой микроскопии. Обработка изображений с помощью Image Analysis показала, что с увеличением концентрации $\mathrm{Al}$ в пленках $\mathrm{ZnO}$ высота неровностей пленок уменьшается. Усредненные значения высоты неровностей $S$ уменьшаются от 16.5 нм до 6.6 нм при увеличении концентрации $\mathrm{Al}$ от 1 до 5 ат.\% (Табл. 2). Сравнивать эти численные значения с результатами расчетов размеров зерен из рентгенограммы не вполне корректно, но тенденция к уменьшению размеров зерен поликристалла $\mathrm{ZnO}$ при увеличении содержания $\mathrm{Al}$ подтверждается.

\section{4. Электрические свойства $\mathrm{ZnO}$ с примесью Al}

В соответствии с данными рентгеноструктурного анализа свежеприготовленные пленки частично кристаллизованы, поэтому их электрические параметры легко измеряются. В Табл. 2 приведены значения слоевого $\left(r_{s}\right)$ и удельного $(\rho)$ сопротивления всех 10 образцов с различным содержанием примеси алюминия. Из Табл. 2 следует, что наименьшим удельным сопротивлением $\left(4 \cdot 10^{-3}\right.$ Ом·см $)$ обладают образцы с концентрацией $\mathrm{Al}$ 1 ат.\%. Сувеличением концентрации примеси $\mathrm{Al}$ удельное электросопротивление образцов непрерывно увеличивается и достигает значения 260 Ом.см при 5 ат.\% Al.

Увеличение электросопротивления пленок $\mathrm{ZnO}$ при увеличении концентрации $\mathrm{Al}$ более 1 ат.\% наблюдалось раннее $[7,9,17]$. В этих работах предполагается, что 1 ат.\% $\mathrm{Al}$ соответствует пределу растворимости атомов $\mathrm{Al}$ в решетке $\mathrm{ZnO}$, когда трехвалентный $\mathrm{Al}^{3+}$ может замещать атомы двухвалентного $\mathrm{Zn}^{2+}$ и выступать в качестве однозарядного донора. Избыточный сверх 1 ат.\% алюминий не замещает атомы Zn в узлах решетки $\mathrm{ZnO}$, а размещается в междоузлиях кристаллической решетки $\mathrm{ZnO}$ и взаимодействует с донорными кислородными вакансиями, что уменьшает генерацию свободных носителей зарядов. Размещение избыточного $\mathrm{Al}$ в междоузлиях кристалла $\mathrm{ZnO}$ должно приводить к деформации кристаллической решетки, что подтверждается данными рентгеноструктурного анализа, свидетельствующими об искажении параметров кристаллической решетки при увеличении концентрации $\mathrm{Al}$ в $\mathrm{ZnO}$.

В пленках $\mathrm{ZnO}$ с отклонением от стехиометрического состава кислородные вакансии образуют мелкий донорный уровень и являются причиной $n$-типа проводимости $\mathrm{ZnO}$ [18]. Поэтому образование комплексов $\mathrm{Al}_{i}-\mathrm{V}_{\mathrm{O}}$ приводит к снижению концентрации

Табл. 2. Значения поверхностного и удельного сопротивления образцов.

Table 2. Values of surface and resistivity of samples.

\begin{tabular}{|c|c|c|c|c|c|c|c|c|c|c|}
\hline $\begin{array}{l}\text { Номер образца } \\
\text { Sample number }\end{array}$ & 1 & 2 & 3 & 4 & 5 & 6 & 7 & 8 & 9 & 10 \\
\hline $\begin{array}{l}\mathrm{Al}, \text { ат.\% } \\
\mathrm{Al}, \text { at.\% }\end{array}$ & 0.9 & 1.14 & 1.32 & 1.97 & 2 & 2.42 & 3.05 & 3.75 & 4 & 5 \\
\hline $\begin{array}{c}r_{s}, \mathrm{OM} / \square \\
r_{s}, \mathrm{Ohm} / \square\end{array}$ & 17 & 18 & 20 & 65 & 60 & 100 & 1500 & $6 \cdot 10^{4}$ & $1.8 \cdot 10^{5}$ & $2 \cdot 10^{6}$ \\
\hline $\begin{array}{c}d, \text { мкм } \\
d, \mu \mathrm{m}\end{array}$ & 2.2 & 2.2 & 2.3 & 2.37 & 2.4 & 2.3 & 2.1 & 1.8 & 1.35 & 1.3 \\
\hline $\begin{array}{c}\text { Содержание } \mathrm{Al} \\
\mathrm{Al} \text { content }\end{array}$ & \multicolumn{3}{|c|}{ AZO1 } & \multicolumn{3}{|c|}{ AZO2 } & AZO3 & \multicolumn{2}{|c|}{$\mathrm{AZO} 4$} & AZO5 \\
\hline $\begin{array}{l}S, \mathrm{HM} \\
S, \mathrm{~nm}\end{array}$ & \multicolumn{3}{|c|}{16.5} & \multicolumn{3}{|c|}{8.8} & 7.4 & \multicolumn{2}{|c|}{6.6} & - \\
\hline $\begin{array}{c}\rho, \mathrm{OM} \cdot \mathrm{cm} \\
\rho, \mathrm{Ohm} \cdot \mathrm{cm}\end{array}$ & 0.0037 & 0.004 & 0.005 & 0.008 & 0.014 & 0.023 & 0.315 & 10.8 & 24.3 & 260 \\
\hline$n$ & \multicolumn{3}{|c|}{2.03} & \multicolumn{3}{|c|}{2.01} & 1.84 & \multicolumn{2}{|c|}{2.04} & 2.05 \\
\hline
\end{tabular}


кислородных вакансий и к уменьшению концентрации свободных носителей зарядов, что наблюдается в наших экспериментах, а также в работах $[7,9,17]$. При этом уменьшение концентрации заряженных донорных центров может приводить к изменению механизма рассеивания свободных носителей зарядов и к возрастанию величины подвижности электронов, что наблюдалось в работе [7].

Влияние кислородных вакансий на величину электросопротивления пленок $\mathrm{ZnO}: \mathrm{Al}$ наглядно показано в работе [17], где отжиг пленок $\mathrm{ZnO}: \mathrm{Al}$ в вакууме приводит к увеличению количества кислородных вакансий и к росту концентрации свободных носителей на 1-2 порядка величины в пленках $\mathrm{ZnO}$, легированных примесью $\mathrm{Al}$ до 5 ат.\%.

Из Табл. 2 следует, что пленки $\mathrm{ZnO}$ с концентрацией примеси $\mathrm{Al}(1 \div 2)$ ат.\% характеризуются величиной удельного сопротивления $\rho=(4 \div 14) \cdot 10^{-3}$ Ом $\cdot$ см, что сопоставимо с удельным сопротивлением пленок ITO $\left(\mathrm{In}_{2} \mathrm{O}_{3}+10 \% \mathrm{SnO}_{2}\right)$, содержащих дорогостоящих индий [19] и применяемых в качестве прозрачных электропроводящих покрытий.

\section{5. Оптические свойства пленок $\mathrm{ZnO}: \mathrm{Al}$}

Bce синтезированные пленки $\mathrm{ZnO}: \mathrm{Al}$ прозрачны в видимом диапазоне. Спектры пропускания света некоторыми образцами AZO приведены на Рис. 4.

Все спектры характеризуются порогом пропускания света в интервале $350 \div 400$ нм и прозрачностью в видимом диапазоне $70 \div 95 \%$. Это свойство пленок AZO позволяет использовать их в прозрачной электронике и в солнечной энергетике.

Наличие интерференционных полос в спектрах пропускания обусловлено интерференцией света при отражении от поверхности пленки и от границы раздела с подложкой. При известной толщине пленок и нормальном падении света на их поверхность соответствующие расчеты [20] позволяют оценить значение коэффициента преломления $n$ пленок AZO.

$$
n=\frac{1}{2 d} \frac{1}{\left(\lambda_{2}^{-1}-\lambda_{1}^{-1}\right)},
$$

где $\lambda_{1}$ и $\lambda_{2}-$ длины волн, соответствующие соседним максимумам; $d-$ толщина пленки.

В Табл. 2 представлены коэффициенты преломления $n$ для различных образцов для длины волны 500 нм. Среднее значение $n=1.9 \pm 0.1$, что соответствует литературным данным [21].

Спектры пропускания (Рис. 4) можно перестроить в спектры поглощения света, зная толщину пленок и учитывая прямозонную структуру оптических переходов в $\mathrm{ZnO}$ (Рис. 5). Из спектров поглощения можно определить ширину запрещенной зоны полупроводника и её зависимость от содержания примеси алюминия. Из результатов эксперимента следует, что примесь $\mathrm{Al}$ в $\mathrm{ZnO}$ приводит к небольшому увеличению ширины запрещенной зоны $\mathrm{ZnO}\left(E_{g}=3.34 \pm 0.3\right.$ эВ), что согласуется с результатами других авторов $[7,9,16]$, согласно

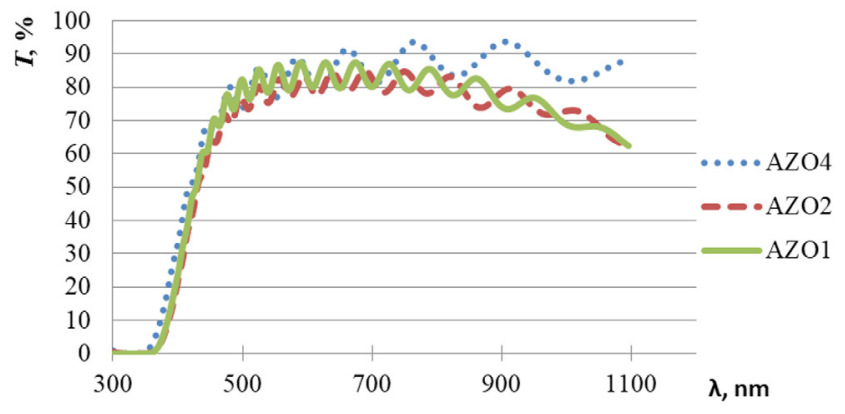

Puc. 4. (Color online) Спектры пропускания пленок $\mathrm{ZnO}: \mathrm{Al}$ для образцов $\mathrm{AZO} 4, \mathrm{AZO} 2, \mathrm{AZO} 1$.

Fig. 4. (Color online) Transmission spectra of $\mathrm{ZnO}: \mathrm{Al}$ films for samples AZO4, AZO2, AZO1.

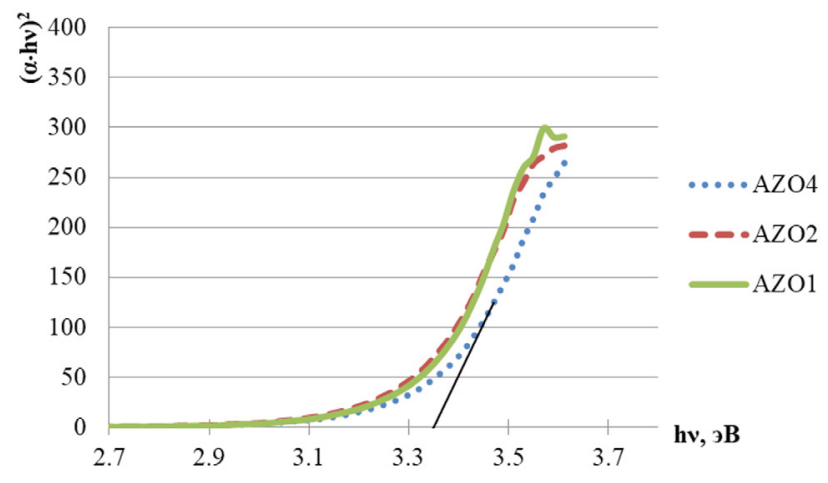

Pиc. 5. (Color online) Спектры поглощения пленок $\mathrm{ZnO}: \mathrm{Al}$ для образцов AZO4, AZO2, AZO1.

Fig. 5. (Color online) Absorption Spectra of $\mathrm{ZnO}: \mathrm{Al}$ Films for Samples AZO4, AZO2, AZO1.

которым ширина запрещенной зоны изменяется в диапазоне $3.17 \div 3.37$ эВ.

На всех спектрах поглощения света пленками AZO при энергиях световых квантов менее значений ширины запрещенной зоны наблюдается экспоненциальная полоса поглощения (полоса Урбаха) [20]. Полоса Урбаха объясняется переходами между хвостами зон, форма и величина которых зависит от легирования полупроводникового материала. Уширения запрещенной зоны за счет эффекта Бурштейна-Мосса [17,22] представляется маловероятным, так как с увеличением концентрации Al число свободных носителей падает, а не растет, и степень вырождения носителей в образцах $\mathrm{ZnO}$ уменьшается.

Из Рис. 5 также следует, что с ростом концентрации $\mathrm{Al}$ в $\mathrm{ZnO}$ увеличивается полоса Урбаха, свидетельствующая, в частности, о локальных напряжениях кристаллической решетки [20]. В работе [7] проведены расчеты значений энергии Урбаха и показано, что вклад разупорядочения в пленке $\mathrm{ZnO}$ растет с увеличением концентрации $\mathrm{Al}$.

\section{6. Заключение}

Методом ионно-лучевого распыления в атмосфере аргона составных керамических мишеней в одном технологическом режиме изготовлены пленки $\mathrm{ZnO}$ с содержанием Al от 1 до 5 ат.\% Свежеприготовленные 
пленки частично кристаллизованы, характеризуются одной фазой с гексагональной решеткой вюрцита с увеличенными параметрами $a$ и $c$. Оценка размеров зерен из рентгенограмм показала, что с увеличением концентрации $\mathrm{Al}$ от 1 до 5 ат.\% средний размер зерен уменьшается от 21.3 нм до 8.5 нм. Такая же тенденция наблюдается по результатам анализа морфологии поверхности с помощью атомно-силовой микроскопии.

Измерение электрических параметров пленок $\mathrm{ZnO}$ с примесью $\mathrm{Al}$ показало, что наименьшим удельным сопротивлением $\rho \sim 4 \cdot 10^{-3}$ Ом·см обладают образцы с 1 ат.\% Al, которые могут использоваться в качестве токопроводящих прозрачных $(T \sim 80 \div 90 \%$ в видимом диапазоне) покрытий в прозрачной электронике и в солнечной энергетике. Рассмотрена возможная причина увеличения электросопротивления пленок $\mathrm{ZnO}$ при возрастании концентрации $\mathrm{Al}$ более 1 ат.\% за счет образования комплексов $\mathrm{Al}_{i}-\mathrm{V}_{\mathrm{O}}$ Оптические свойства пленок $\mathrm{ZnO}: \mathrm{Al}$ показали их высокую прозрачность в видимом диапазоне света $(T \sim 80 \div 90 \%)$ и небольшое увеличение ширины запрещенной зоны по мере увеличения концентрации Al. Приведена оценка величины коэффициента преломления $\mathrm{ZnO}: \mathrm{Al}$, и получены значения $n=1.9 \pm 0.1$.

Таким образом, пленки $\mathrm{ZnO}$ с $1 \div 2$ ат.\% примеси $\mathrm{Al}$ по своим электрическим и оптическим свойствам могут служить заменой дорогостоящих пленок ITO $\left(\mathrm{In}_{2} \mathrm{O}_{3}+10 \% \quad \mathrm{SnO}_{2}\right)$, использующихся в качестве проводящих прозрачных покрытий и оптических окон в фотовольтаике.

\section{Литература/References}

1. Z. L. Wang. J. Phys. Condens. Matter 2016. 16, 829 (2004). Crossref

2. S.T. Shishiyanu, T.S. Shishiyanu, O.I. Lupan. Sens. Actuator B-Chem. 107, 379 (2005). Crossref

3. J.F. Wager. Science. 300, 1245 (2003). Crossref

4. L. J. Mandalapu, Z. Yang, S. Chu, J. L. Liu. Appl. Phys. Lett. 92, 122101 (2008). Crossref

5. K. L. Foo, M. Kashif, U. Hashim, W. W. Liu. Ceram Int. 40, 753 (2014). Crossref

6. Y. Liu, Y. Li, H. Zeng. J. Nanomater. 2013, 196521 (2013). Crossref

7. T. Jannanea, M. Manoua, A. Liba, N. Fazouan, A. El Hichou, A. Almaggoussi, A. Outzourhit, M. Chaik. J. Mater. Environ. Sci. 8 (1), 160 (2017).
8. N. A. Lashkova, A. I. Maximov, A. A. Ryabko, A. A. Bobkov, V.A. Moshnikov, E. I. Terukov. Semiconductors. 50, 1254 (2016). (in Russian) [Н.А. Лашкова, А.И. Максимов, А.А. Рябко, А.А. Бобков, В.А. Мошников, Е.И. Теруков. Физика и техника полупроводников. 50 (9), 1276 (2016).] Crossref

9. F. Choikh, Y. Beggah, M.S. Aida. Int. J. Thin Film Sci. Tech. 3 (2), 51 (2014). Crossref

10. P. Gondoni, M. Ghidelli, F. Di Fonzo, V. Russo, P. Bruno, J. Marth-Rujas, C.E. Bottani, A. Li Bassi, C.S. Casari. Thin Solid Films. 520, 4707 (2012). Crossref

11. X. Wang, X. Zeng, D. Huang, X. Zhang, Q. Li. J. Mater. Sci. Mater. Electron. 23, 1580 (2012). Crossref

12. A. A.-G. Farrag, M. Balboul. J. Sol-Gel Sci. Technol. 82, 269 (2017). $\underline{\text { Crossref }}$

13. J. C. Fan, K. M. Sreekanth, Z. Xie, S.L. Chan, K. V. Rao. Prog. Mater. Sci. 58, 874 (2013). Crossref

14. A.D. Pogrebnjak, A.A. Muhammed, E.T. Karash, N. Y. Jamil, J. Partyka. Przeglad Elektrotechniczny. 89 (3), 315 (2013).

15. I. V. Babkina, O. V. Zhilova, Y. Y. Kalinin, V. A. Makagonov, O. I. Remizova, A. V. Sitnikov. Letters on Materials. 8 (2), 196 (2018). (in Russian) [И. В. Бабкина, О.В.Жилова, Ю.Е. Калинин, В.А. Макагонов, О.И. Ремизова, А.В. Ситников. Письма о материалах. 8 (2), 196 (2018).] Crossref

16. I.S. Ilyaushev, Yu.E. Kalinin, V.A. Makagonov, S. Yu. Pankov, A. V. Sitnikov. Bulletin of Voronezh state technical University. 13 (5), 100 (2017). (in Russian) [И.С. Ильяшев, Ю.Е. Калинин, В.А. Макагонов, С. Ю. Панков, А. В. Ситников. Вестник Воронежского государственного технического университета. 13 (5), 100 (2017).]

17. S. Mridha, D. Basak. J. Phys. D. Appl. Phys. 40, 6902 (2007). Crossref

18. W.H. Hirschwald. Acc. Chem. Res. 18 (8), 228 (1985). Crossref

19. C.-L. Tang, H.-Y. Lin, C.-K. Chang, C.-J. Tang. Adv. Condens. Matter Phys. 2018, 2647282 (2018). Crossref

20. J. I. Pankove. Optical processes in semiconductors. New Jersey, Englewood Cliffs (1971) 422 p.

21. N. Baydogan, T. Ozdurmusoglu, H. Cimenoglu. Defect and Diffusion Forum. 334-335, 290 (2013). Crossref

22. I. Juhnevica, M. Masonkina, G. Mezinskis, A. Gabrene. Material Science and Applied Chemistry. 31, 33 (2015). $\underline{\text { Crossref }}$ 